\title{
Spatially and temporally resolved degradation in antisolvent treated perovskite films
}

DOI:

$10.1117 / 12.2553682$

\section{Document Version}

Accepted author manuscript

Link to publication record in Manchester Research Explorer

\section{Citation for published version (APA):}

Choi, H., Ke, C., Skalsky, S., Flavell, W. R., \& Parkinson, P. (2020). Spatially and temporally resolved degradation in antisolvent treated perovskite films. In Proceedings Volume 11365, Organic Electronics and Photonics:

Fundamentals and Devices II (pp. 27) https://doi.org/10.1117/12.2553682

\section{Published in:}

Proceedings Volume 11365, Organic Electronics and Photonics: Fundamentals and Devices II

\section{Citing this paper}

Please note that where the full-text provided on Manchester Research Explorer is the Author Accepted Manuscript or Proof version this may differ from the final Published version. If citing, it is advised that you check and use the publisher's definitive version.

\section{General rights}

Copyright and moral rights for the publications made accessible in the Research Explorer are retained by the authors and/or other copyright owners and it is a condition of accessing publications that users recognise and abide by the legal requirements associated with these rights.

\section{Takedown policy}

If you believe that this document breaches copyright please refer to the University of Manchester's Takedown Procedures [http://man.ac.uk/04Y6Bo] or contact uml.scholarlycommunications@manchester.ac.uk providing relevant details, so we can investigate your claim.

\section{OPEN ACCESS}




\title{
Spatially and temporally resolved degradation in antisolvent treated perovskite films
}

\author{
Hoyeon Choi ${ }^{\mathrm{a}}$, Chun-Ren $\mathrm{Ke}^{\mathrm{a}}$, Stefan Skalsky ${ }^{\mathrm{a}}$, Wendy Flavell ${ }^{\mathrm{a}}$, and Patrick Parkinson*a \\ a Department of Physics and Astronomy and the Photon Science Institute, The University of \\ Manchester, Oxford Road, Manchester, M13 9PL, United Kingdom
}

\begin{abstract}
Material and functional stability remains a major issues in field of perovskite photovoltaics. To achieve a long device lifetime, it is crucial that we understand and optimize the lifetime of the material itself. One-step antisolvent processing is a facile method to enhance stability. Herein, we report that changes in the degradation process of perovskite films is modified by the antisolvent treatment in comparison to the conventional film without the process which we measure by monitoring the emission. Perovskite films prepared with anti-solvent processing have improved film morphology and reduced evolution of surface metallic lead, which correlated with improved film lifetimes.
\end{abstract}

Keywords: Perovskite, photovoltaics, degradation, antisolvent, confocal scanning microscope

\section{INTRODUCTION}

Recent progress in the development of photovoltaics based on organic-inorganic hybrid perovskite has enabled power conversion efficiencies (PCE) exceeding $23 \%$ which is close to that of conventional thin-film solar cells based on polycrystalline silicon, $\mathrm{CdTe}$, and $\mathrm{Cu}(\mathrm{InGa}) \mathrm{Se}_{2} \cdot{ }^{1-3}$ However, significant issues remain, with perovskite photovoltaics having a poor long-term stability due to the active perovskite material. This in turn has hinderd the production of commercial products in which the other counterparts provide a 25 years warranty for reliable efficiency. ${ }^{4}$ The stability has been shown to be reduced by multiple environmental substances, such as moisture and oxygen, which can be controlled by encapsulation, as well as inevitable factors which result from the device operation, for instance, heat, light, and applied bias. ${ }^{1,2,4,5}$

According to recent work from Watson and co-workers, in an organic-inorganic hybrid perovskite, a fabrication process with an antisolvent which can absorb moisture, ${ }^{6}$ (in particular ethyl acetate (EA) $)^{2,7}$ ) can prevent deformation of the perovskite structure during crystal growth and boost crystallization. ${ }^{8} 9$ Furthermore, the hydrophobic nature of EA in the perovskite film can effectively maintain the film stability. ${ }^{7}$ Therefore, the perovskite films fabricated with the EA shows the higher crystal quality and enhanced stability, demonstrating both superior device performance, and elongated life time. ${ }^{2}$

A number of characterization techniques, such as UV-Vis, X-ray photoelectron spectroscopy (XPS), and X-ray crystallography (XRD), have been employed to investigate the degradation process of hybrid perovskite..$^{5,10-12}$ Photoluminescence (PL) quenching can provide insite into the photodegradation process of methylammonium lead triiodide $\left(\mathrm{CH}_{3} \mathrm{NH}_{3} \mathrm{PBI}_{3}, \mathrm{MAPI}\right)$ crystal, ${ }^{1,5,10}$ since the degradation process involving $\mathrm{H}_{2} \mathrm{O}$ cause the conversion geminate MAPI into $\mathrm{PbI}_{2}$ which barely emits PL. ${ }^{12}$ Scanning confocal PL microscopy provides a map of local property changes and mophological feature of the perovskite film. Since the EA solvent significantly changes the morphology of the film, this techniques provides a direct observation of the heterogeneous behaviour depending on the local structure during the aging process. ${ }^{2,7}$ The evolution in the emission spectrum associated with the morphology can also explain the local degradation process of MAPI. Water molecules continuously etch the grain boundary, ${ }^{13}$ and the residual of the process $\left(\mathrm{PbI}_{2}\right)$ promotes the deformation of the core crystal. ${ }^{14}$ This happens from the surface to the core of individual perovskite crystals, ${ }^{13}$ thereby, the emission spectrum undergoes blueshifting. ${ }^{4}$

Further author information: (Send correspondence to Dr. Patrick Parkinson)

Dr. Patrick Parkinson : E-mail: patrick.parkinson@manchester.ac.uk 
To correlate the second-scale evolution with sub-nanosecond emission energetics, we employ our newly developed interferometric-time correlated single photon counting (iTCSPC) combined with the confocal microscopy on the film. This technique shows that the real-time evolution in the emission energy shift can be correlated with changes in carrier lifetime and intensity; together, these support that the reduction in emission intensity with short fluorescence lifetime are both associated with degradation due to the moisture. ${ }^{12,15}$

Here, we report the stability enhancement in the perovskite film with one-step antisolvent process, and the changes in morphology during the degradation. In comparison to the conventional perovskite film without the EA treatment, the superior stability of the sample produced by the process can be attributed to the good crystal quality and morphology.

\section{RESULTS AND DISCUSSIONS}

To monitor the changes in PL evolution with respect to the morphological features, we capture sequential PL images from the same region with illumination of a monochromatic continuous wave (CW) laser with photon energy at $2 \mathrm{eV}$, and a power of $280 \mu \mathrm{W}$. With this excitation beam we can consider the degradation process primarily associated with the environmental substances, rather than the illumination, since the CW laser with photon energy below $2.40 \mathrm{eV}$ is known to be less sensitive to photodegradation. ${ }^{16}$ For each image, we studied regions of each sample with dimension corresponding to their feature sizes. For the pristine sample (without anti-solvent) this led to images of $25 \times 25 \mu \mathrm{m}^{2}$ being acquired every 8 minutes with resolution of $0.5 \mu \mathrm{m}$ and for the anti-solvent treated samples this led to $50 \times 50 \mu \mathrm{m}^{2}$ being acquired every 60 minutes with resolution $0.5 \mu \mathrm{m}$. This corresponds to an irradiation per image of $3.7 \mathrm{~J} \mathrm{~cm}^{-2}$ and $6.0 \mathrm{~J} \mathrm{~cm}^{-2}$ for the pristine and the sample with EA respectively.

Figure 1 shows the PL evolution from each samples. Since the PL quenching combined with blue shifting is strong evidence of degradation, ${ }^{1,4,12}$ it can be observed that the film without EA shows poor stability, fully degrading within a few hundred minutes, whereas the EA treated sample maintains the string PL up to 1500 mins in ambient air. In Figure 1e, f, the peak emission wavelength of the both samples blueshifted; however, the variation of emission $(\sim 0.015 \mathrm{eV})$ in the pristine sample is about 7 times greater than that of the one with EA $(\sim 0.002 \mathrm{eV})$. Furthermore, we can see the PL enhancement during the acquisition in EA treated sample, which can be attributed to the photoinduced effect. ${ }^{16}$

The morphology of the samples are shown in Figure 2a,b. In the scanning electron microscopy (SEM) images, the two samples show different morphologies; the sample with the EA shows a flat surface, while the pristine sample has distinctive bone-like structures present on the surface. X-ray photoelectron spectroscopy (XPS) was performed to probe the surface chemistry of the MAPI films fabricated with or without EA. As shown in Figure $2 \mathrm{c}$ for the $\mathrm{Pb} 4 \mathrm{f}$ spectra, it can be seen that the sample without EA has a significant fraction of metallic lead at the surface while the EA treated film do not give any metallic lead signals. The binding energy of the metallic lead component fitted $\left(\mathrm{Pb} 4 f_{7 / 2}\right.$, red) is located at $\sim 137.0 \mathrm{eV}$, consistent with the value in the previous literature. ${ }^{10}$ This suggests that the surface without the antisolvent treatment has degraded from MAPI during fabrication. In addition, the MAPI Pb $4 f_{7 / 2}$ component (green) should sit at a binding energy of $\sim 138.6 \mathrm{eV} .{ }^{10}$ This is the case for the EA treated MAPI, but not the case for the pristine sample. For the latter, the $\mathrm{Pb}_{2}{ }^{+}$peak has a slightly higher binding energy of $138.7 \mathrm{eV}$, suggesting partial formation of $\mathrm{PbI}_{2}$. The result of $\mathrm{I} / \mathrm{Pb}$ and $\mathrm{N} / \mathrm{Pb}$ shown in Table. 1 confirms this degradation from MAPI to $\mathrm{PbI}_{2}$. The values are much lower than the nominal stoichiometric values for MAPI and more closer to those of $\mathrm{PbI}_{2}$, different from the antisolvent treated film that exhibits stoichiometric values of $\sim 3.0$ and 1.0 for $\mathrm{I} / \mathrm{Pb}$ and $\mathrm{N} / \mathrm{Pb}$, respectively. The anti-solvent process appears to prevent the degradation of MAPI surfaces during ambient air fabrication.

Table $1 . \mathrm{I} / \mathrm{Pb}$ and $\mathrm{N} / \mathrm{Pb}$ ratios of the MAPI films with/without EA

\begin{tabular}{|l|l|l|}
\hline MAPI & $\mathrm{I} / \mathrm{Pb}$ & $\mathrm{N} / \mathrm{Pb}$ \\
\hline Pristine & $2.5 \pm 0.1$ & $0.5 \pm 0.1$ \\
\hline with EA & $3.0 \pm 0.1$ & $1.0 \pm 0.1$ \\
\hline
\end{tabular}



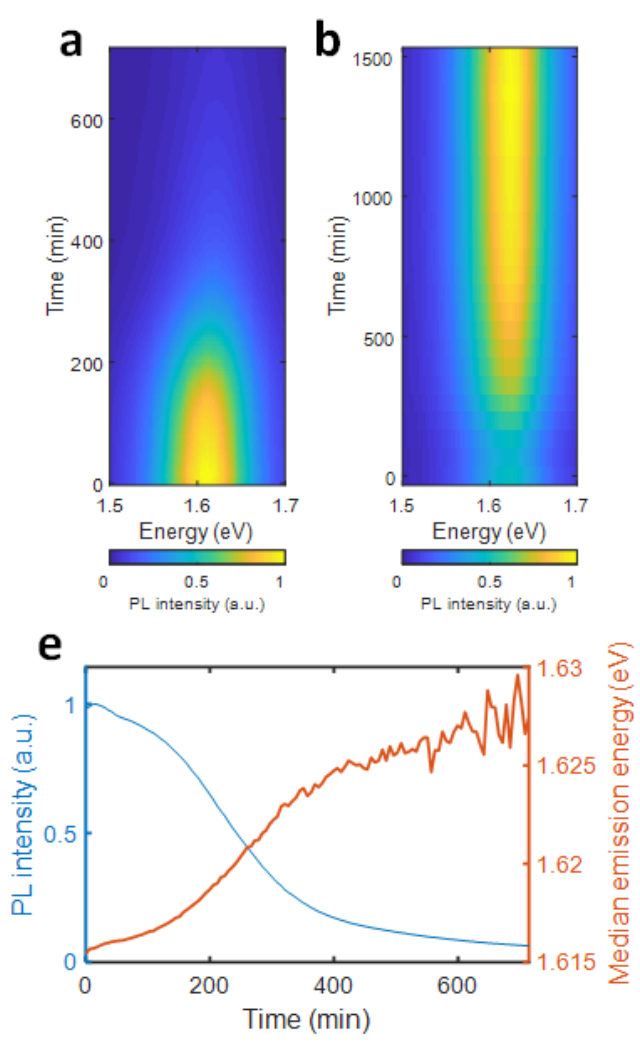

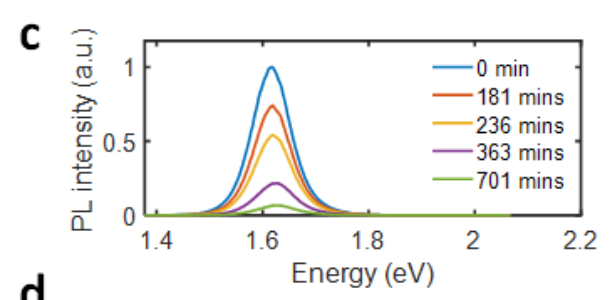

d
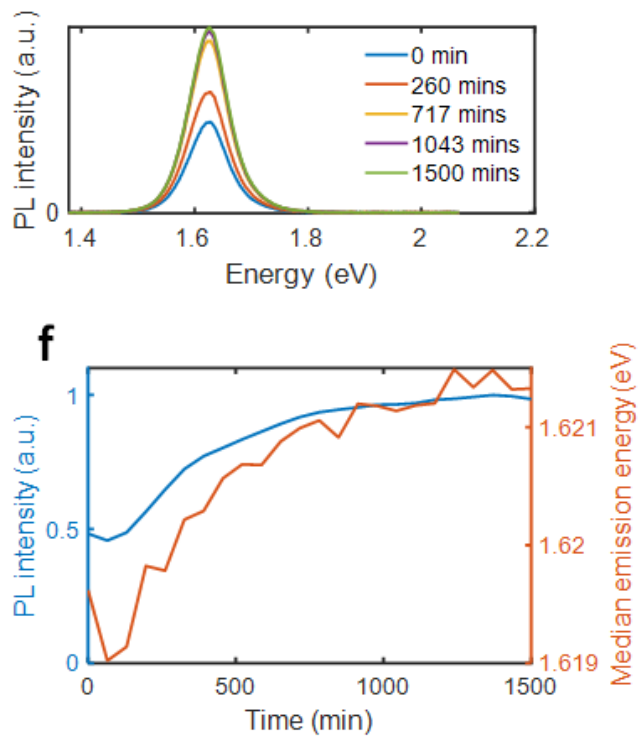

Figure 1. An overview of the PL due to degradation process under $2 \mathrm{eV}$ excitation in ambient conditions. Spectral changes in the pristine perovskite film (a), and the film with EA (b). (c), (d) the sorted PL spectrum of the pristine and with EA, respectively. (e), (f) the evolution of net PL intensity and median emission energy.

The spatially-resolved evolution in PL intensity and median energy (defined as $E_{e m}=\frac{\sum_{i} I\left(E_{i}\right) \cdot E_{I}}{\sum_{i} I\left(E_{i}\right)}$ where $I\left(E_{I}\right)$ is the intensity at each energy $\left.E_{i}\right)$ as a function of exposed time in ambient air is shown in Figure 3 . At the initial stage (0 min in Figure 3), the PL is uniformly emitted across the scanned area in the EA treated sample, whereas the sample without EA shows strong and lower energy emission from the bone-like structures which has the similar shape to the features observed in SEM image in Figure 2a. The emission from those structures reduced rapidly after exposure in ambient air; simultaneously emission shifts to higher energy and the bright feature shrink during the degradation process, in comparison, the EA treated sample shows sustainable emission.

The fluorescence lifetime is shown in Figure 4. To measure the emission lifetime, $80 \mathrm{ps}$ pulsed laser illumination at $3.06 \mathrm{eV}$ with a repetition rate of $1 \mathrm{MHz}$ and an average power of $1.1 \mu \mathrm{W}$ were used. The sample with EA shows long lifetime of $69.8 \pm 0.3 \mathrm{~ns}$ in comparison to the sample without EA of which the fluorescence lifetime is $21.9 \pm 0.1 \mathrm{~ns}$. The lifetime were obtained using a biexponential fitting function $I(t)=P_{1} \exp \frac{-t}{\tau_{1}}+P_{2} \exp \frac{-t}{\tau_{2}}$ (where $I(t)$ is the intensity of the detected fluorescence, $P_{1,2}$ are the amplitudes, and $\tau_{1,2}$ are the decay times. The $\tau_{\text {avg }}$, is the average lifetime.) After exposure in ambient air for 120 mins, the lifetime in the pristine samples further drops to $16.8 \pm 0.1 \mathrm{~ns}$. This long lifetime in the EA treated sample can be attributed to the large grain domains in the sample, the addition of EA associated with free carrier recombination in MAPI. ${ }^{17}$ The reduction of the carrier lifetime accompanied by a significant blueshift can can be associated with the reduced size of the grains by etching due to moisture. ${ }^{13,15}$ The spectrally resolved iTCSPC data in Figure 4b-d confirms that the emission occurs primarily from the a single band, and no changes in spectra occurs as a function of time after excitation. 

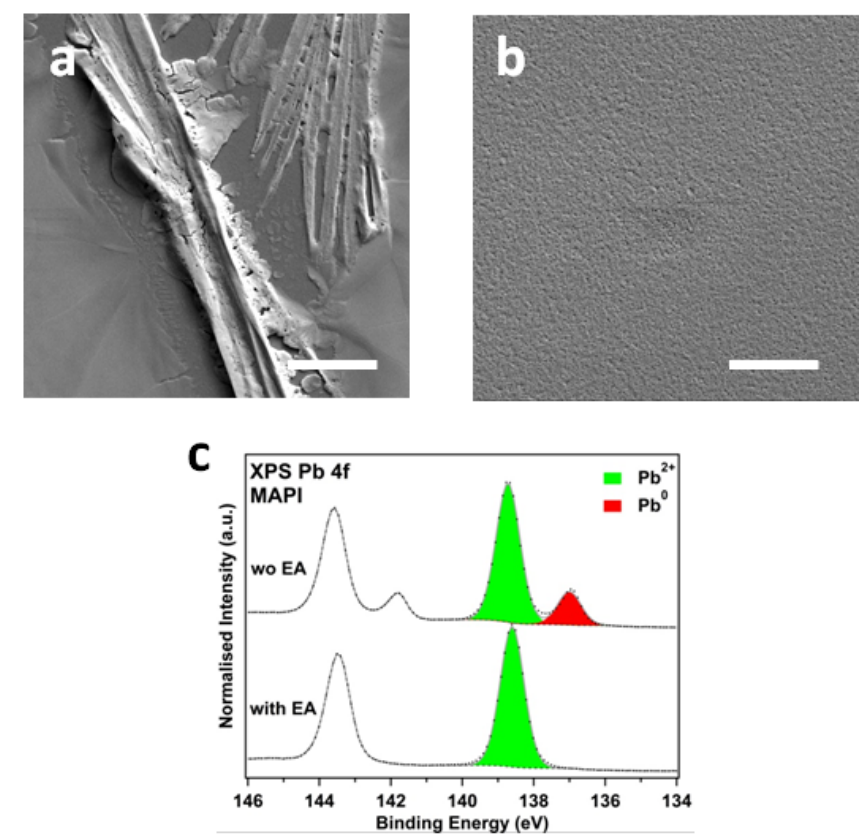

Figure 2. The SEM images of the pristine perovskite film (a) and the EA treated film (b), The scale bars are $10 \mu \mathrm{m}$ in length. XPS Pb $4 \mathrm{f}$ spectra of spin-coated MAPI films prepared with EA and without EA (c).

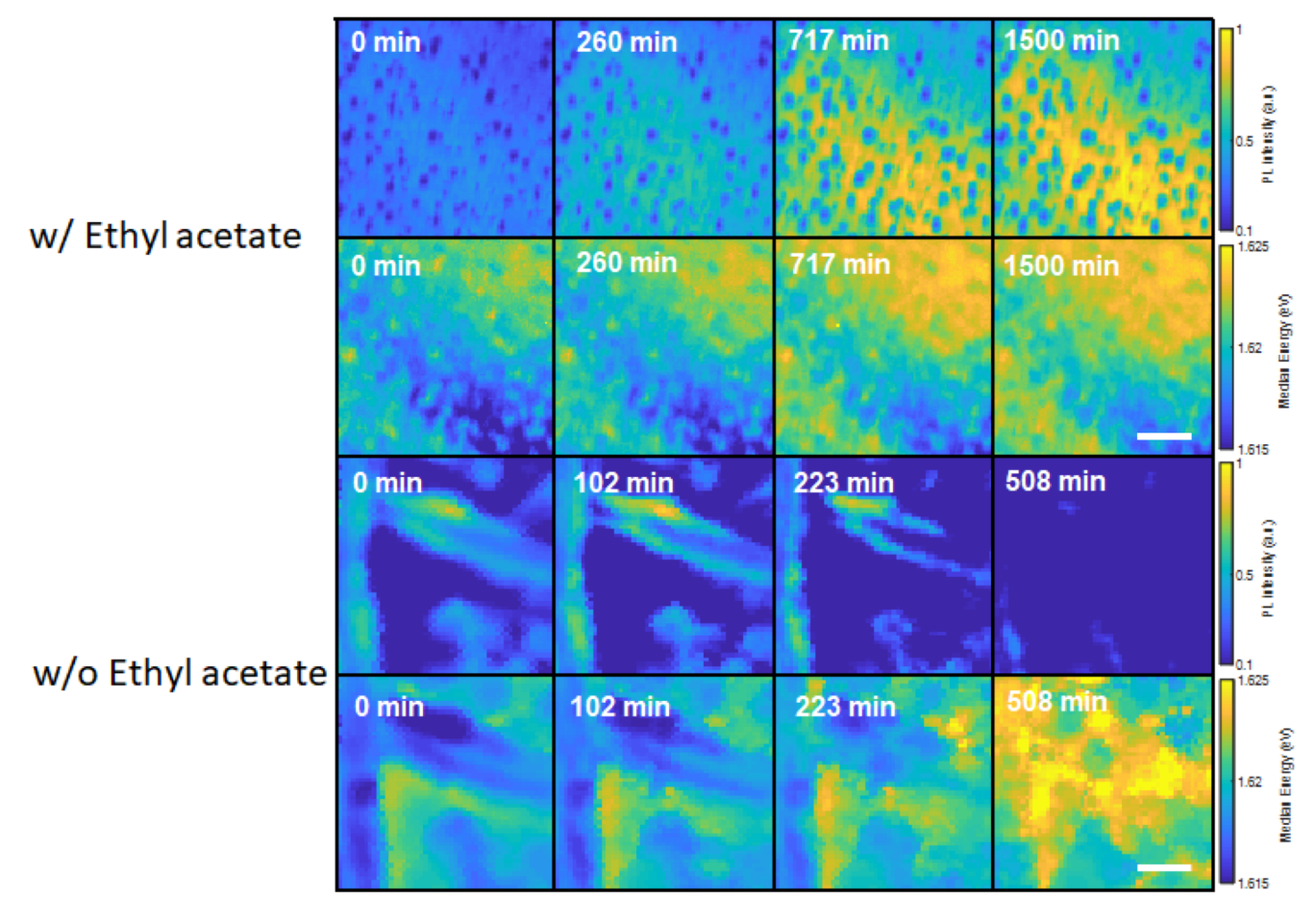

Figure 3. Intensity (1st and 3rd row) and median emission energy maps (2nd and 4th row) for the EA treated sample (upper two rows) and the pristine sample without EA treatment (lower 2 rows) showing images from the degradation map. The scale bar is $12.5 \mu \mathrm{m}$ for the EA treated sample (upper two rows) and $6.25 \mu \mathrm{m}$ for the pristine sample. (lower 2 rows) 
a

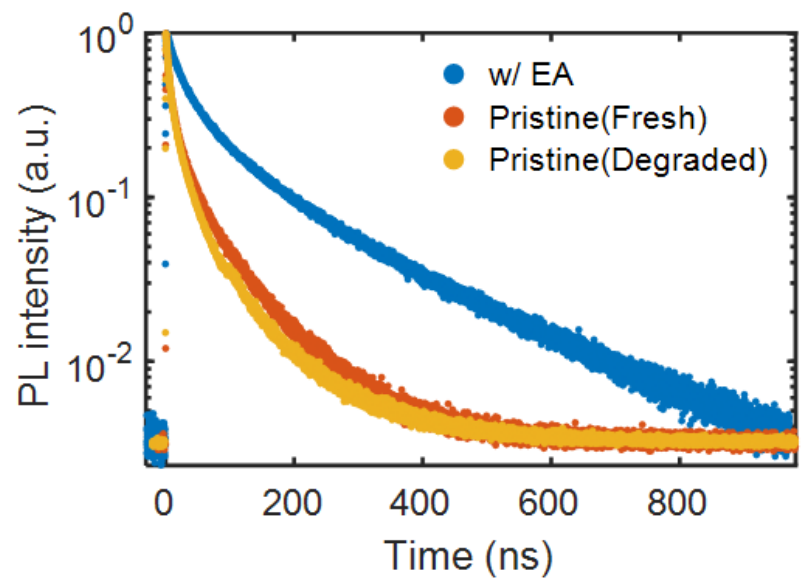

b
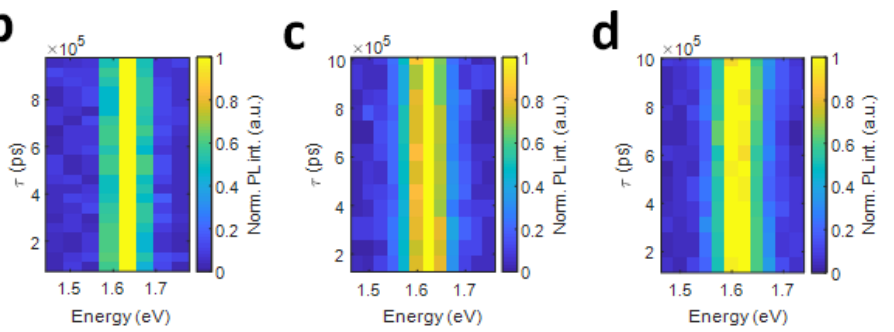

Figure 4. (a) The emission lifetime of the studied perovskite films. The spectral resolved lifetime changes in the sample with EA (b), the fresh pristine sample (c) and the degraded pristine sample in ambient air for 2 hrs (d)

Table 2. The fluorescence lifetime of the samples in Figure 4.

\begin{tabular}{|l|l|l|l|}
\hline Sample & $\tau_{1}(n s)$ & $\tau_{2}(n s)$ & $\tau_{\text {avg }}(\mathrm{ns})$ \\
\hline w/EA & $25.2 \pm 0.1$ & $149.8 \pm 0.1$ & $69.8 \pm 0.3$ \\
\hline Pristine(Fresh) & $7.6 \pm 0.1$ & $57.6 \pm 0.2$ & $21.9 \pm 0.1$ \\
\hline Pristine(degraded) & $6.4 \pm 0.1$ & $43.2 \pm 0.3$ & $16.8 \pm 0.1$ \\
\hline
\end{tabular}

\section{CONCLUSION}

In conclusion, by combining multiple microscale characterization techniques, we investigated how the EA treatment used in the fabrication of MAPI films enhance the stability of the film. XPS, confocal scanning microscopy and SEM images shows that the film with EA has a uniform surface, whereas the pristine film without the antisolvent process has poor morphology with abundant $\mathrm{PbI}_{2}$. Under exposure to ambient air, the MAPI structures on the surface of the pristine film starts degrading within 100 minutes which was confirmed by decrease in the intensity of emission and increase in the center of emission energy. Concomitantly, the weighted emission lifetime is reduced from $21.90 \pm 0.09 \mathrm{~ns}$ to $16.8 \pm 0.1 \mathrm{~ns}$. Taken together, this implies that the $\mathrm{H}_{2} \mathrm{O}$ driven grain etching process in the pristine perovskite film begins rapidly in untreated films. ${ }^{13}$ However, the EA treated sample has superior stability which exceed the given monitoring time of 1500 mins. Furthermore the weighted emission lifetime of $69.8 \pm 0.3 \mathrm{~ns}$ is much longer than that of the pristine film of $21.9 \pm 0.1 \mathrm{~ns}$, which is beneficial for the high performance and stable photovoltaic devices. 


\section{EXPERIMENTAL SECTION}

\subsection{Sample preparation}

For PL experiments, perovskite samples were prepared on z-cut quartz substrates. For the SEM characterization the perovskite sample were deposited on top of indium tin oxide (ITO). All substrates were thoroughly cleaned via common cleaning processes used in fabrication of perovskite solar cells: First, the substrates were ultrasonicated for 10 mins in Helimax III (3 vol \% in deionised (DI) water), DI water, and acetone. Subsequently, the washed substrates were dried using dry air, followed by $\mathrm{UV}-\mathrm{O}_{3}$ treatment for 15 minutes in order to remove the residual organics prior to deposition of the MAPI films.

\subsubsection{MAPI perovskite film}

All the fabrication processes in this work were conducted in ambient air with relative humidities of at least greater than 50\%. First, $230 \mathrm{mg}$ of lead iodide $\left(\mathrm{PbI}_{2}, 99.9985 \%\right.$, Alfa Aesar) was dissolved in a mixture of $400 \mu \mathrm{l}$ anhydrous N,N-dimethylformamide (DMF, 99.8\%, Sigma-Aldrich) and $100 \mu \mathrm{l}$ anhydrous dimethyl sulfoxide (DMSO, 99.9\%, Sigma-Aldrich) at $70^{\circ} \mathrm{C}$ with stirring for 30 minutes to generate a clear yellow solution $(1.0 \mathrm{M})$. Subsequently, a stoichiometric amount $(80 \mathrm{mg}, 1.0 \mathrm{M})$ of methylammonium iodide (MAI, 98\%, Ossila) powders was added into the solution under continuous stirring for another 30 minutes at room temperature to form MAPI for use in spin coating. Prior to spin coating, the substrates were heated at $70{ }^{\circ} \mathrm{C}$ on a hot place for at least 5 minutes before spin coating. In the spin coating steps, a small volume $(50 \mu \mathrm{l})$ of the perovskite solution was poured on the warm substrate and the film was then spun at $4000 \mathrm{rpm}$ for 30 seconds. During spinning, a $200 \mu \mathrm{l}$ of an antisolvent, anhydrous ethyl acetate (99.8\%, Sigma-Aldrich), was dripped on the spinning sample at approximately 8 seconds following starts of the spin-coating process. Subsequently, the as-deposited samples were transferred to a hot plate for annealing at $100^{\circ} \mathrm{C}$ in ambient air for 10 minutes.

\subsection{Characterization}

\subsubsection{Scanning electron microscopy(SEM)}

The morphology of the MAPI films (by AACVD, and spin coating) deposited on ITO-coated glasses was probed using a Zeiss Sigma SEM instrument, with an acceleration voltage of $10 \mathrm{kV}$ using secondary electron images.

\subsubsection{XPS characterization}

XPS measurements were performed with Kratos Axis Ultra XPS instrument, equipped with a monochromated AL $K \alpha$ X-ray source (photon energy $=1486.6 \mathrm{eV}$ ). Emitted photo electrons were collected using a $165 \mathrm{~mm}$ hemispherical energy energy analyser (Kratos). Binding energies were calibrated to well-define Au $4 f_{7 / 2}$ at $84.0 \mathrm{eV} \cdot{ }^{18}$

\subsubsection{Confocal scanning microscopy}

The confocal PL image were taken with a home-built scanning microscope. A He-Ne continuous wave laser at $632.8 \mathrm{~nm}$ was employed to excite the sample. The excitation beam is split by two 50:50 beam-splitters; the first divides the beam to the sample and an integrated power meter. The sample stage is attached to a encoded $x y$ stage, and a $60 \times$ objective lens (Olympus) is attached to a stepper-motor controlled $z$ axis. The 3 -dimensional control are allows 3D scanning in which the spatial resolution of the translation stage is $\sim 100 \mathrm{~nm}$. Fluorescence emitted from the sample was split by the second beam splitter. One branch was detected to a fibre coupler with $\sim 30 \times$ magnification; this could be coupled to a spectrometer (Ocean Optics) through an multimode optical fibre of diameter $105 \mu \mathrm{m}$, to give a detection collection diameter of $\sim 3.5 \mu \mathrm{m}$. The other beam branch was simultaneously monitored using a CCD camera.

\subsection{4 i-TCSPC}

A $405 \mathrm{~nm}$ pulsed diode laser at a frequency of $500 \mathrm{kHz}$ and pulse duration $80 \mathrm{ps}$ was used to excite the samples. The same sample stage of confocal scanning microscope was used to excite and detect the samples. Instead of the spectrometer, a single-mode optical fibre was used to transport the photoluminescence signal to the i-TCSPC system. Briefly, a folded-Michelson interferometer with dual channel SPAD (idQuantique 100) detectors was combined with TCSPC (Hydraharp 400) hardware in T2 mode. The interferometer was continually scanned, and each detected photon was binned according to arrival time, channel and interferometer position; this permits spectral, decay and kinetics to be resolved in post-processing. 


\section{REFERENCES}

[1] Wang, R., Mujahid, M., Duan, Y., Wang, Z.-K., Xue, J., and Yang, Y., "A review of perovskites solar cell stability," Advanced Functional Materials 29(47), 1808843 (2019).

[2] Troughton, J., Hooper, K., and Watson, T. M., "Humidity resistant fabrication of $\mathrm{CH}_{3} \mathrm{NH}_{3} \mathrm{PbI}_{3}$ perovskite solar cells and modules," Nano Energy 39, 60-68 (2017).

[3] Wang, P., Li, R., Chen, B., Hou, F., Zhang, J., Zhao, Y., and Zhang, X., "Gradient energy alignment engineering for planar perovskite solar cells with efficiency over 23\%," Advanced Materials , 1905766 (2020).

[4] Sun, Q., Fassl, P., Becker-Koch, D., Bausch, A., Rivkin, B., Bai, S., Hopkinson, P. E., Snaith, H. J., and Vaynzof, Y., "Role of microstructure in oxygen induced photodegradation of methylammonium lead triiodide perovskite films," Advanced Energy Materials 7(20), 1700977 (2017).

[5] Niu, G., Guo, X., and Wang, L., "Review of recent progress in chemical stability of perovskite solar cells," Journal of Materials Chemistry A 3(17), 8970-8980 (2015).

[6] Zhang, W., Li, Y., Liu, X., Tang, D., Li, X., and Yuan, X., "Ethyl acetate green antisolvent process for high-performance planar low-temperature $\mathrm{SnO}_{2}$-based perovskite solar cells made in ambient air," Chemical Engineering Journal 379, 122298 (2020).

[7] Yang, F., Kapil, G., Zhang, P., Hu, Z., Kamarudin, M. A., Ma, T., and Hayase, S., "Dependence of acetatebased antisolvents for high humidity fabrication of $\mathrm{CH}_{3} \mathrm{NH}_{3} \mathrm{PbI}_{3}$ perovskite devices in ambient atmosphere," ACS applied materials \& interfaces 10(19), 16482-16489 (2018).

[8] Yin, M., Xie, F., Chen, H., Yang, X., Ye, F., Bi, E., Wu, Y., Cai, M., and Han, L., "Annealing-free perovskite films by instant crystallization for efficient solar cells," Journal of Materials Chemistry A 4(22), 8548-8553 (2016).

[9] Dong, C., Han, X., Li, W., Qiu, Q., and Wang, J., "Anti-solvent assisted multi-step deposition for efficient and stable carbon-based $\mathrm{CsPbI}_{2} \mathrm{Br}$ all-inorganic perovskite solar cell," Nano Energy 59, 553-559 (2019).

[10] Ke, J. C.-R., Walton, A. S., Lewis, D. J., Tedstone, A., O’Brien, P., Thomas, A. G., and Flavell, W. R., "In situ investigation of degradation at organometal halide perovskite surfaces by x-ray photoelectron spectroscopy at realistic water vapour pressure," Chemical Communications 53(37), 5231-5234 (2017).

[11] Matsumoto, F., Vorpahl, S. M., Banks, J. Q., Sengupta, E., and Ginger, D. S., "Photodecomposition and morphology evolution of organometal halide perovskite solar cells," The Journal of Physical Chemistry C 119(36), 20810-20816 (2015).

[12] Gujar, T. P., Unger, T., Schönleber, A., Fried, M., Panzer, F., van Smaalen, S., Köhler, A., and Thelakkat, M., "The role of $\mathrm{PbI}_{2}$ in $\mathrm{CH}_{3} \mathrm{NH}_{3} \mathrm{PbI}_{3}$ perovskite stability, solar cell parameters and device degradation," Physical Chemistry Chemical Physics 20(1), 605-614 (2018).

[13] Wang, Q., Chen, B., Liu, Y., Deng, Y., Bai, Y., Dong, Q., and Huang, J., "Scaling behavior of moistureinduced grain degradation in polycrystalline hybrid perovskite thin films," Energy \& Environmental Science 10(2), 516-522 (2017).

[14] Liu, F., Dong, Q., Wong, M. K., Djurišić, A. B., Ng, A., Ren, Z., Shen, Q., Surya, C., Chan, W. K., Wang, J., et al., "Is excess $\mathrm{PbI}_{2}$ beneficial for perovskite solar cell performance?," Advanced Energy Materials 6(7), 1502206 (2016).

[15] Yuan, H., Debroye, E., Janssen, K., Naiki, H., Steuwe, C., Lu, G., Moris, M., Orgiu, E., Uji-i, H., De Schryver, F., et al., "Degradation of methylammonium lead iodide perovskite structures through light and electron beam driven ion migration," The journal of physical chemistry letters 7(3), 561-566 (2016).

[16] Quitsch, W.-A., deQuilettes, D. W., Pfingsten, O., Schmitz, A., Ognjanovic, S., Jariwala, S., Koch, S., Winterer, M., Ginger, D. S., and Bacher, G., "The role of excitation energy in photobrightening and photodegradation of halide perovskite thin films," The journal of physical chemistry letters $\mathbf{9 ( 8 ) , 2 0 6 2 - 2 0 6 9}$ (2018).

[17] Yamada, Y., Nakamura, T., Endo, M., Wakamiya, A., and Kanemitsu, Y., "Photocarrier recombination dynamics in perovskite $\mathrm{CH}_{3} \mathrm{NH}_{3} \mathrm{PbI}_{3}$ for solar cell applications," Journal of the American Chemical Society 136(33), 11610-11613 (2014).

[18] Ke, J. C.-R., Lewis, D. J., Walton, A. S., Spencer, B. F., O’Brien, P., Thomas, A. G., and Flavell, W. R., "Ambient-air-stable inorganic $\mathrm{Cs}_{2} \mathrm{SnI}_{6}$ double perovskite thin films via aerosol-assisted chemical vapour deposition," Journal of Materials Chemistry A 6(24), 11205-11214 (2018). 